\title{
Net Worth Ratio and Financial Instability
}

\author{
Toshio Watanabe
}

Received: 31 July 2012 / Accepted: 19 February 2013 / Published online: 15 March 2013

(C) 2013 T. Watanabe; licensee Springer. This is an Open Access article distributed under the terms of the Creative Commons Attribution License (http://creativecommons.org/licenses/by/2.0), which permits unrestricted use, distribution, and reproduction in any medium, provided the original work is properly cited.

\begin{abstract}
In order to better understand relationships between the real economy and financial economy, it is necessary to formulate a model of financing. New Keynesian theory emphasizes that a firm's net worth influences investment decisions and business cycles under an imperfect capital market. We have constructed a dynamic model from the standpoint of post Keynesian economics. We incorporate a dynamic equation of a firm's net worth ratio and investigate financial factors, which give rise to economic instability. Our results demonstrate that a steady state can be a saddle point when the dividend rate is low and the bank's lending reaction to the net worth ratio is more elastic than investment reaction. When the steady state is the saddle, the change in the basic discount rate is likely to shift the economy from an unstable path to a convergence path. Financial policy has a stabilizing effect in the long-run as well as a positive effect in the short-run.
\end{abstract}

Keywords Bank behavior · Investment · Unstable economy · Monetary policy

JEL Classification E12 $\cdot$ E44 $\cdot$ E52

\section{Introduction}

Financial markets in market economies gain in complexity and have significant effects on the real economy. From the standpoint of new Keynesian economics, Greenwald and Stiglitz [8] as well as Bernanke and Gertler [3] pointed out that the investment and output of rational firms depend on the firms' balance sheet factors under an imperfect capital market.

T. Watanabe $(\bowtie)$

Hirao School of Management, Konan University, 8-33, Takamatsu-cho, Nishinomiya-city,

Hyogo-ken 663-8204, Japan

e-mail: toshio@ center.konan-u.ac.jp 
It is hardly new to discuss the interactions between financial markets and the real economy. Keynes [10] rejected classical economics and indicated the instability of the real economy; especially, he emphasized the instability of financial markets. In general, a firm's behavior depends not only on balance sheet factors, which new Keynesian pointed out, but also on bank behavior and other factors.

Minsky [12] analyzed the effects of financial factors on the economy. He alleged that financial booms and collapses become inevitable in market economies. In this respect, he is in the post Keynesian group, which emphasizes instability of the economy. He investigated the financing of investments and the cyclical behavior of the real economy. He developed a new theory called the financial instability hypothesis, which involved the argument of Fisher [7] as well as Keynes.

Minsky's ideas lead to the development of various mathematical models. ${ }^{1}$ For example, Taylor and O'Connell [15] and Adachi [1] focused on long-run expectations and household portfolios. Though Adachi constructed a model with explicit inclusion of bank behavior, his model is too complex to show concisely the dynamic economy and stabilizing effects of monetary policy.

In this paper, we highlight net worth, which is line with new Keynesian theory. However, we focus on the net worth ratio, which is the ratio of net worth to capital of a firm. One of the purposes of this paper is to build a simple macro model on the net worth ratio from the standpoint of post Keynesian economics. We investigate financial factors, which give rise to instability of the economy. We formulate a model of investment decisions, bank behavior, and financing for better understanding of the relations between real economy and financial economy.

Our model has assumptions that are similar to Greenwald and Stiglitz. The equity market is imperfect. Firms cannot raise new equity and normally pay a dividend on existing shares. Meanwhile, there is a bank lending market. The firms can borrow as much as they want, but they must pay interests. Hence, the evolution of net worth is represented by retained earnings.

The second purpose of this paper is to analyze the effectiveness of monetary policy. We first construct a static model, and then extend to a dynamic model that incorporates dynamic equations of both the net worth ratio and bank lending rate. ${ }^{2}$ This dynamic model is similar to that of Taylor and O'Connell and Adachi. We investigate the effects of monetary policy on the short-run and long-run equilibrium; especially, we consider a stabilizing effect of monetary policy when the steady state is unstable.

Our results demonstrate that the economy can be unstable when the dividend rate is low and the bank's lending reaction to the net worth ratio is more elastic than investment reaction. The latter factor is a feature of our model. When the steady state is a saddle point, the change in the basic discount rate is likely to shift the economy from an unstable path to a convergence path. ${ }^{3}$ We can see that financial policy has a stabilizing effect in the long-run as well as a positive effect in the short-run.

\footnotetext{
${ }^{1}$ Other than Taylor and O'Connell [15] and Adachi [1], discussed below, these include Delli Gatti and Gallegati [4] and Lavoie [11].

${ }^{2}$ There are various types of dynamic models. For example, Kaldor [9] is one of the typical dynamic models. Asada [2] developed a Kaldorian cycle model and investigated the effects of government economic policy. Our dynamic model differs from them. Instead, we follow Taylor and O'Connell [15] and Adachi [1].

${ }^{3}$ We describe the interest payment of the central bank advances as the basic discount rate.
} 
This paper is organized in the following manner. Section 2 presents an overview of the model we are proposing. Section 3 discusses the respective behavior of firms, banks, and households. We derive the investment function, bank lending function, and so on. In Sects. 4 and 5, we consider the equilibrium of commodity market and bank lending market, respectively. Section 6 analyzes the equilibrium of the short-run economy. Section 7 investigates the instability of economy. We construct a dynamic system and consider a stabilizing effect of monetary policy. Finally, Sect. 8 summarizes the results.

\section{Description of the Model}

The economic system in this paper consists of 4 sectors (firms, banks, households, and central bank) and 5 markets (commodities, bank lending, deposits, cash currency, and central bank advances).

The firm maximizes the present value of returns from investment and decides a capital accumulation rate. The investment is financed through either retained earnings or borrowings from the bank. There is a time-lag between borrowing and interest payment. The firm pays interest on previous borrowings during present period. The firm decides the capital accumulation rate and new borrowings from bank during present period given the existing capital stock and previous bank lending rate.

The bank decides the lending to maximize profits. The household saves in the form of either deposits or cash currency. We assume that the deposit rate is regulated and that the bank accepts all deposits, which the household would like to make. In addition, in the market of central bank advances, we assume that the basic discount rate is exogenously determined as a means of monetary policy and the central bank supplies funds, which the bank requests. This type of monetary policy fits with the concept of "the horizontalist view."

Table 1 presents simplified balance sheets for economic agents. To analyze our dynamic system, we specify how the net worth ratio of the firm and the bank lending rate evolve over time.

\section{Structure}

\subsection{Investment Decisions of Firm ${ }^{4}$}

We assume an imperfectly competitive firm and there is markup pricing at a constant rate $\tau$ over the labor cost. The nominal wage is $\omega$, the labor is $N$, the output is $Y$, labor-output ratio is $n .^{5}$ The price level $p$ is given by

$$
p=(1+\tau) \omega n, \quad n=N / Y .
$$

The firm makes an investment, given the existing capital stock. The investment decisions of the firm are made based on expected returns over the periods during

\footnotetext{
${ }^{4}$ This formulation follows Adachi [1].

${ }^{5}$ We assume that $\tau, \omega$, and $n$ are constant throughout this paper.
} 
Table 1 Simplified balance sheets

\begin{tabular}{llll}
\hline Central bank & Firm & \\
\hline Central bank advances $A^{s}$ & $\begin{array}{l}\text { Bank reserves } R \\
\text { Cash currency } M^{s}\end{array}$ & Capital $p K$ & $\begin{array}{l}\text { Debt } L \\
\text { Equity } E_{q} \\
\text { Earned surplus } E_{S}\end{array}$ \\
\hline Private bank & Heposit $D^{h}$ & Household & Wealth $W$ \\
\hline $\begin{array}{l}\text { Lending } L^{b} \\
\text { Bank reserves } R\end{array}$ & Central bank advances $A^{b}$ & $\begin{array}{l}\text { Cash currency } M^{h} \\
\text { Deposit } D^{h}\end{array}$ & \\
& & Equity $E_{q}$ & \\
\hline
\end{tabular}

which the newly installed equipment will be used. But they cannot get returns when they make bad investments and go bankrupt. Let us denote the expected returns of investment by $Q$, and the possibility of bankruptcy by $\sigma$. The sequence of returns from investment is given by $\left\{Q,(1-\sigma) Q,(1-\sigma)^{2} Q, \ldots\right\}$.

The present value of returns from investment is written as

$$
P V=\sum_{j=1}^{\infty} Q(1-\sigma)^{j-1} /(1+r)^{j}=Q /(r+\sigma),
$$

where $r$ is the bank lending rate at which the firm borrows during present period.

We assume that the risk premium $\sigma$ depends on the net worth ratio $z$, which is the ratio of net worth $Z$ to the existing capital stock $p K$. The firm's net worth is the sum of the value of equity $E_{q}$ and earned surplus $E_{s}$. The earned surplus is the accumulation of retained earnings. When the net worth ratio is low, the possibility of bankruptcy is high. The risk premium is represented by

$$
\begin{aligned}
& \sigma=\sigma(z), \quad \sigma_{z}<0, z=Z / p K, \\
& Z=E_{q}+E_{s} .
\end{aligned}
$$

Additionally, we assume that the ratio of expected return of investment to the existing capital stock depends on the capital accumulation rate $k$ which is the investment per unit of capital. It can be represented by

$$
Q / p K=\phi(k), \quad \phi_{k}>0, \phi_{k k}<0, k=I / K,
$$

where $I$ is the investment. We assume that the marginal efficiency of capital $\phi_{k}$ decreases as $k$ increases.

Taking into account Eqs. (3) and (5) to Eq. (2), we can express the present value of the net cash flow from investment as

$$
\Pi^{f}=Q /(r+\sigma)-p I=[\phi(k) /(r+\sigma(z))-k] p K .
$$

Maximizing $\Pi^{f}$ with respect to $k$ yields

$$
\phi_{k}(k)=r+\sigma(z) \text {. }
$$


The left-hand side of Eq. (7) indicates the marginal efficiency of capital and righthand side indicates the marginal cost. The capital accumulation rate $k$ can be expressed as

$$
k=k(r, z), \quad k_{r}<0, k_{z}>0 .
$$

The capital accumulation rate is a decreasing function of the bank lending rate and an increasing function of the net worth ratio.

\subsection{The Financing of Investment}

When the capital market is imperfect, the Modigliani-Miller theorem [13] is not true. In other words, under an imperfect capital market, the independence of investment and financing is lost. We have to consider the relations between investment and financing.

We assume that the equity is issued only when the firm is established. The firm cannot raise new equity and pay a dividend on existing shares. On the other hand, there is a bank lending market. The firm borrows from a bank and pays interests. ${ }^{6}$

All investments must be financed through either retained earnings or borrowings from bank. This is represented by

$$
p I=F+\Delta L^{d}
$$

where $F$ is retained earnings and $\Delta L^{d}$ is new borrowings from the bank during the present period. The total borrowings $L^{d}$ are written as

$$
L^{d}=L+\Delta L^{d}
$$

where $L$ is debt.

The retained earnings are calculated as the difference between the total income and the sum of labor costs, the interest payment, and the dividend. This is represented by

$$
F=p Y-\omega N-\bar{r} L-V,
$$

where $\bar{r}$ is the bank lending rate during the previous period and $V$ is the dividend.

The firm distributes the constant rate $v$ of profit as a dividend to shareholders. We can express the dividend as

$$
V=v(p Y-\omega N-\bar{r} L) .
$$

Substituting Eq. (12) into Eq. (11), we obtain

$$
F=(1-v)(p Y-\omega N-\bar{r} L) .
$$

Additionally, substituting Eqs. (1), (10) and (11') into Eq. (9) and dividing by $p K$, we obtain

$$
k=(1-v)\left(\frac{\tau}{1+\tau}\right) y-(1-v) \bar{r} l+l^{d}-l, \quad y=Y / K, l=L / p K, l^{d}=L^{d} / p K,
$$

\footnotetext{
${ }^{6}$ As discussed in the Introduction, these assumptions are based on Greenwald and Stiglitz [8].
} 
where $y$ is output-capital ratio and $l$ is debt-capital ratio.

From the firm's balance sheet, the debt-capital ratio $l$ is equal to 1 minus net worth ratio. This is represented by

$$
l=1-z .
$$

Substituting Eqs. (8) and (14) into Eq. (13), we can express the borrowing demand function as ${ }^{7}$

$$
\begin{aligned}
& l^{d}=k(r, z)-(1-v)\left(\frac{\tau}{1+\tau}\right) y+\{(1-v) \bar{r}+1\}(1-z), \\
& l_{y}^{d}<0, l_{r}^{d}<0, l_{z}^{d} \lesseqgtr 0, l_{\bar{r}}^{d}>0 .
\end{aligned}
$$

The borrowings from bank are a decreasing function of the bank lending rate during the present period and an increasing function of the bank lending rate in the previous period. The effect of net worth ratio will be ambiguous, because the increase of net worth ratio has effects on increase of investment as well as decrease of existing debt.

\subsection{Bank Behavior}

Like firms, banks seek profits. The bank earns revenue from lending to firms and makes interest payments to depositors and the central bank. We take into account the transition costs $G$. The costs involve auditing and monitoring costs to firms and losses in the event of corporate failures.

For the sake of simplicity, we assume that the deposit interest is regulated and bank accepts all deposits, which the household would like to make. The profit of bank per unit of capital $\pi^{b}$ is given by

$$
\begin{aligned}
& \pi^{b}=r l^{b}-i^{d} d^{h}-i^{a} a^{b}-g, \\
& \pi^{b}=\Pi^{b} / p K, \quad l^{b}=L^{b} / p K, d^{h}=D^{h} / p K, a^{b}=A^{b} / p K, g=G / p K,
\end{aligned}
$$

where $\Pi^{b}$ is profit of bank, $L^{b}$ is bank lending, $i^{d}$ is deposit rate, $D^{h}$ is deposit from the household, $i^{a}$ is the basic discount rate, and $A^{b}$ is the central bank advances.

Let us consider the cost function $g$. First, the costs in auditing and monitoring generally depend on the level of bank lending. We assume that the cost $g$ is an increasing function of bank lending-capital ratio. Second, the bank's risk premium for lending is high when the bank estimates that the possibility of the firm's bankruptcy is high. We assume that the bank's risk premium depends on the net worth ratio of the firm. When the net worth ratio is low, the bank's risk premium becomes high. The cost $g$ increases as the net worth ratio decreases. Then the cost function $g$ is written as

$$
g=g\left(l^{b}, z\right), \quad g_{l^{b}}>0, g_{l^{b} l^{b}}>0, g_{z}<0, g_{l^{b} z}<0 .
$$

\footnotetext{
${ }^{7}$ We suppose that investment exceeds retained earnings. In other words, $l^{d}>0$.
} 
We assume that the marginal cost of bank lending increases more than proportionally as $l^{b}$ increases and decreases as $z$ increases.

Substituting Eq. (17) into Eq. (16), we have

$$
\pi^{b}=r l^{b}-i^{d} d^{h}-i^{a} a^{b}-g\left(l^{b}, z\right) .
$$

On the other hand, from bank's balance sheet, we have

$$
L^{b}+R=D^{h}+A^{b},
$$

where $R$ is bank reserves. The bank reserves must be satisfied legal reserve. This is represented by

$$
R=\theta D^{h},
$$

where $\theta$ is legal reserve rate.

Substituting Eq. (20) into Eq. (19) and dividing by $p K$, we obtain

$$
l^{b}=(1-\theta) d^{h}+a^{b} .
$$

To sum up, the problem of bank is to maximize Eq. (18) subject to constraints in Eq. (21). In this problem, bank lending $l^{b}$ and the central bank advances $a^{b}$ are controlled by the bank. The first order condition for a maximum of $\pi^{b}$ is

$$
g_{l^{b}}\left(l^{b}, z\right)=r-i^{a} .
$$

The bank lending can be expressed as

$$
l^{b}=l^{b}\left(r, z, i^{a}\right), \quad l_{r}^{b}>0, l_{z}^{b}>0, l_{i^{a}}^{b}<0 .
$$

Bank lending is an increasing function of the bank lending rate and net worth ratio and a decreasing function of the basic discount rate.

\subsection{Household Behavior}

The household allocates wealth across deposits $D^{h}$ and cash currency $M^{h}$. The present wealth of the household $W$ is the sum of wealth at beginning of period $\bar{W}$ and savings during the present period $p S^{h}$. This is represented by

$$
W=\bar{W}+p S^{h} .
$$

Since we assume that equity is issued only when the firm is established, the amount of equity $E_{q}$ remains unchanged. Therefore, the amount of the present wealth except for the value of equity is allocated to deposits and cash currency. This is represented by

$$
W-E_{q}=D^{h}+M^{h} .
$$

First, let us consider wealth at the beginning of period $\bar{W}$. Taking into account the economy as a whole, the assets which one has is the liability which another has. From the balance sheets of overall economy, the following equation is satisfied:

$$
p K=\bar{W}+E_{s} .
$$


On the other hand, from the firm's balance sheet, we have

$$
p K=E_{q}+E_{s}+L .
$$

Substituting Eqs. (26) and (27) into Eq. (24), we obtain

$$
W-E_{q}=L+p S^{h} .
$$

Additionally, taking into account Eqs. (4) and (27), we have

$$
W-E_{q}=p K-Z+p S^{h} .
$$

Let us next consider present savings of the household $p S^{h}$. The gross income of the firm is distributed to wage and firms' profit. The firm pays interests on bank lending from their profit. The remainder is distributed to stockholders as dividends or held back as retained earnings. We assume that bank revenues shall invest in the household via bank's labor cost and other factors. From these assumptions, the household income $p Y^{h}$ is equal to the gross income minus retained earnings of the firm. This is represented by

$$
p Y^{h}=p Y-(1-v)(p Y-\omega N-\bar{r} L) .
$$

We assume that consumption of the economy as a whole is equal to wage income. The consumption function is written by

$$
p C=\omega N .
$$

Taking into account Eqs. (29) and (30), the savings of the household are expressed as

$$
p S^{h}=\bar{r} L+v(p Y-\omega N-\bar{r} L) .
$$

From Eqs. $\left(28^{\prime}\right)$ and (31), the present wealth of the household except for the value of equity is expressed as

$$
W-E_{q}=p K-Z+\bar{r} L+v(p Y-\omega N-\bar{r} L) .
$$

The portfolio behavior functions follow Tobin [16]. We express the ratio of deposit demand to the household's wealth except for the amount of equity as $\delta$ and assume that $\delta$ is an increasing function of deposit rate $i^{d}$. The demand functions of deposit and cash currency are respectively expressed by

$$
\begin{aligned}
& D^{h}=\delta\left(i^{d}\right)\left(W-E_{q}\right), \quad \delta_{i^{d}}>0, \\
& M^{h}=\left(1-\delta\left(i^{d}\right)\right)\left(W-E_{q}\right) .
\end{aligned}
$$

Taking into account of Eq. (32) and dividing Eqs. (33a) and (33b) by $p K$, we have

$$
\begin{aligned}
& d^{h}=\delta\left(i^{d}\right)\left[v\left(\frac{\tau}{1+\tau}\right) y+\{(1-v) \bar{r}+1\}(1-z)\right], \\
& d_{i^{d}}^{h}>0, d_{z}^{h}<0, d_{y}^{h}>0, d_{\bar{r}}^{h}>0, d^{h}=D^{h} / p K,
\end{aligned}
$$




$$
\begin{aligned}
& m^{h}=\left\{1-\delta\left(i^{d}\right)\right\}\left[v\left(\frac{\tau}{1+\tau}\right) y+\{(1-v) \bar{r}+1\}(1-z)\right], \\
& m_{i^{d}}^{h}<0, m_{z}^{h}<0, m_{y}^{h}>0, m_{\bar{r}}^{h}>0, m^{h}=M^{h} / p K .
\end{aligned}
$$

Since the increase of net worth ratio decreases present household's wealth, both deposits and currency demands will decrease. In contrast, both demands will increase responding to the increase of output-capital ratio and previous bank lending rate.

\section{Equilibrium of Commodity Market}

This economic system consists of 5 markets; commodities, bank lending, deposits, cash currency, and central bank advances. We assume that the deposit rate is regulated and that bank accepts all deposits, which the household would like to make. The supply of deposits is constrained by demand. Similarly, we assume that the basic discount rate is exogenously determined as a means of monetary policy and the central bank supplies funds, which the bank requests.

Therefore, we will consider the equilibriums of 3 markets: commodities, bank lending, and cash currency. Taking into account Walras' law, we can suppress the analysis of cash currency market. We will consider the commodity market and bank lending market.

Let us first consider the commodity market. The commodity market achieves equilibrium when investments and savings are equal. The savings of the economy $p S$ are equal to the sum of the household's savings and retained earnings of the firm. This is represented by

$$
p S=\bar{r} L+v(p Y-\omega N-\bar{r} L)+(1-v)(p Y-\omega N-\bar{r} L)=p Y-\omega N .
$$

Dividing by $p K$, we have

$$
s=\frac{p S}{p K}=\left(\frac{\tau}{1+\tau}\right) y .
$$

Taking into account Eqs. (8) and (35), we can express the balance equation of commodity market as follows:

$$
k(r, z)=\left(\frac{\tau}{1+\tau}\right) y .
$$

When there is excess demand, output-capital ratio $y$ will go up. This adjustment process is represented by

$$
\dot{y}=H(y, r)=k(r, z)-\frac{\tau}{1+\tau} y .
$$

We assume the following condition is satisfied in commodity market to stabilize the adjustment process:

$$
H_{y}=-\frac{\tau}{1+\tau}<0
$$


Fig. 1 IS curve

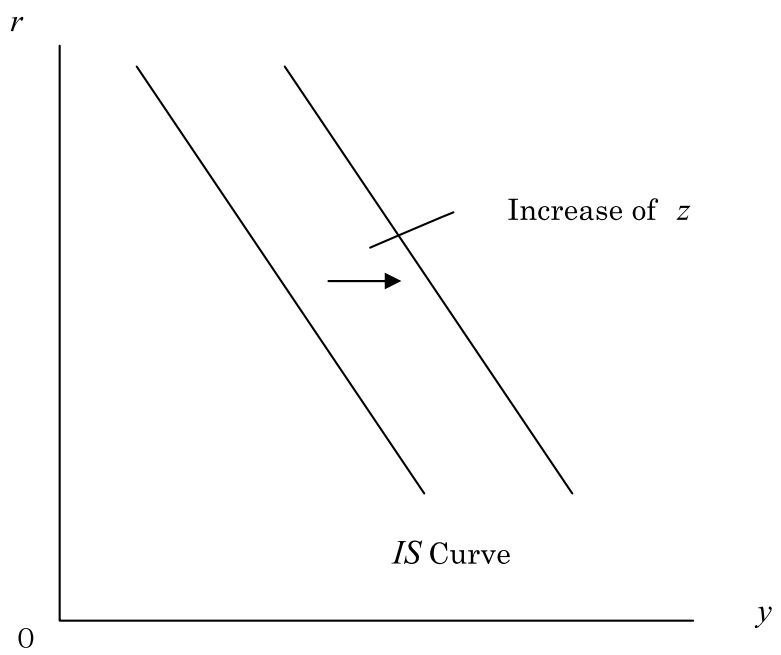

This condition is satisfied at all times. We will draw the balance equation of commodity market on $O y r$ plane in Fig. 1. The slope is downward sloping. We shall call this curve $I S$ curve. When the net worth ratio increases, the $I S$ curve will shift rightward as shown in Fig. 1.

\section{Equilibrium of Financial Markets}

Let us next consider bank lending market as financial market. Taking into account Eqs. (15) and (23), we can express the balance equation of bank lending market as follows:

$$
k(r, z)-(1-v)\left(\frac{\tau}{1+\tau}\right) y+\{(1-v) \bar{r}+1\}(1-z)=l^{b}\left(r, z, i^{a}\right) .
$$

When there is excess demand, the bank lending rate $r$ will go up. This adjustment process is represented by

$$
\dot{r}=X(y, r)=k(r, z)-(1-v)\left(\frac{\tau}{1+\tau}\right) y+\{(1-v) \bar{r}+1\}(1-z)-l^{b}\left(r, z, i^{a}\right) .
$$

We assume the following condition is satisfied in bank lending market to stabilize the adjustment process:

$$
X_{r}=k_{r}-l_{r}^{b}<0 .
$$

This condition is satisfied at all times. We will draw the balance equation of bank lending market in Fig. 2. The slope is downward sloping. We shall call this curve $B L$ curve. When the basic discount rate and the previous bank loan rate increase, the $B L$ curve will shift upward as shown in Fig. 2. On the other hand, the effect of the net worth ratio on the $B L$ curve is ambiguous. The increase of net worth ratio will result in an increase of both bank lending and investment. When the former effect is larger than the latter effect, the $B L$ curve will shift downward. 
Fig. $2 B L$ curve

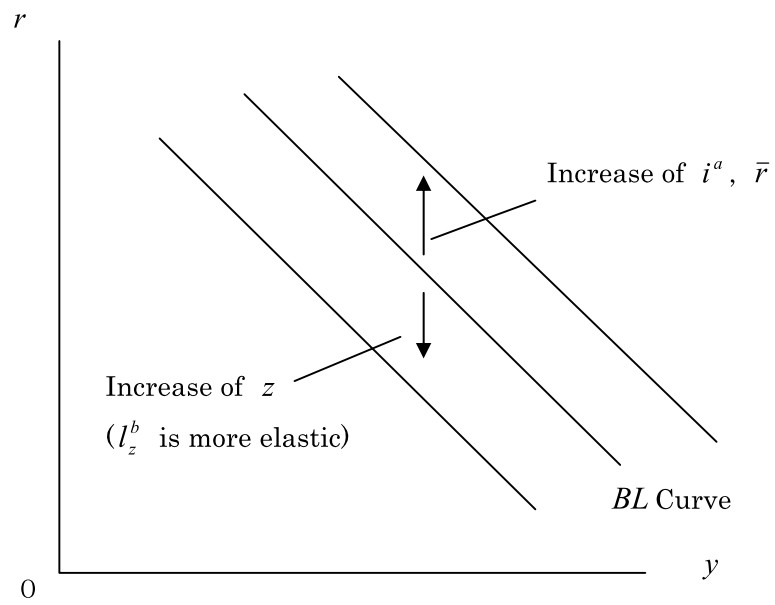

\section{Short-Run Equilibrium and Comparative Statics}

We will now consider short-run equilibrium. The system comprises Eqs. (36) and (39) and determines output-capital ratio $y$ and bank lending rate $r$.

We will first consider the stability of short-run equilibrium. Dynamic equations in a disequilibrium situation are expressed by Eqs. (37) and (40). We can confirm that the short-run equilibrium is stable. ${ }^{8}$ We can express the short-run equilibrium as

$$
\begin{aligned}
& y=y\left(z, \bar{r}, i^{a}\right), \\
& y_{z}>0, y_{\bar{r}}<0, y_{i^{a}}<0, \\
& r=r\left(z, \bar{r}, i^{a}\right), \\
& r_{z} \lesseqgtr 0, r_{\bar{r}}>0, r_{i} a>0 .
\end{aligned}
$$

Figure 3 depicts the short-run equilibrium. The slope of $I S$ curve is higher than that of $B L$ curve when the stability conditions are satisfied.

Let us examine the effect of exogenous variables on short-run equilibrium. When the previous bank lending rate $\bar{r}$ and the basic discount rate $i^{a}$ rise, the $B L$ curve will shift upward. The output-capital ratio will decrease and the present bank lending rate will increase.

We shall examine how the net worth ratio $z$ affects the output-capital ratio and bank lending rate. Though the shift of $B L$ curve is ambiguous when the net worth ratio rises, the output-capital ratio will increase. But the effect on bank lending rate will be ambiguous. ${ }^{9}$ When the effect on bank lending is larger than that on investment, the bank lending rate will decrease. As shown in the following section, the economy can become unstable when the increase of net worth ratio decreases the bank lending rate.

\footnotetext{
${ }^{8}$ Appendix 1 provides the mathematical proof of the stability of short-run equilibrium. ${ }^{9} r_{z}=-\frac{\left\{(1-v) \bar{r}+1+l_{z}^{b}-v k_{z}\right\}}{l_{r}^{b}-v k_{r}}$. When the effect of $l_{z}^{b}$ is larger than that of $k_{z}, r_{z}$ will be negative.
} 
Fig. 3 Short-run equilibrium

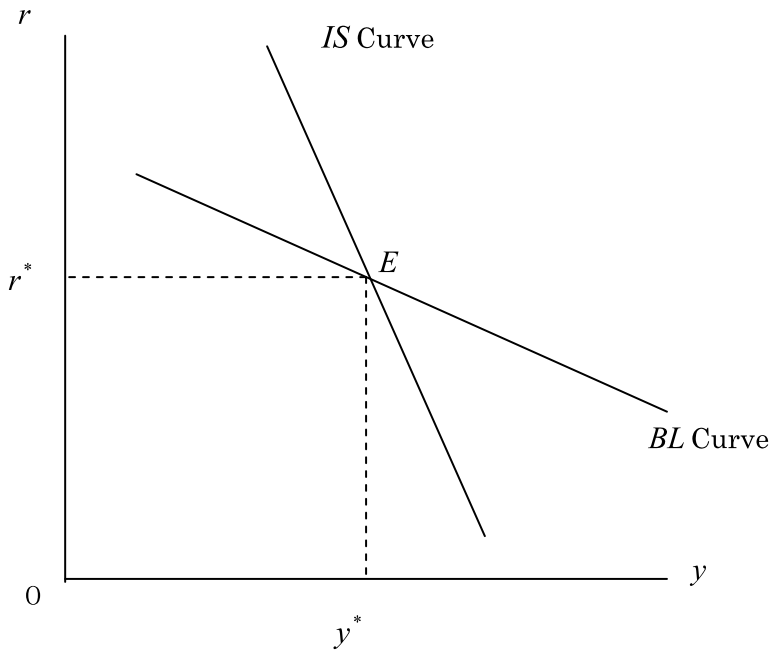

From the static model, we can see that the firm's balance sheet elements and bank behavior significantly affect the real economy as Minsky alleged. In the next section, we will investigate the unstable economy by using a dynamic model.

Proposition 1 In the short-run, when the net worth ratio rises, the output-capital ratio will increase. Additionally, when the previous bank lending rate and the basic discount rate rise, the output-capital ratio will decrease and the present bank lending rate will increase.

\section{Dynamic Model}

\subsection{Stability of Steady State}

In this section, we construct a dynamic model to investigate the mechanism of financial instability. We shall analyze the characteristics of steady state in our model. ${ }^{10}$

In the discussions so far, we treated the net worth ratio $z$ and previous bank lending rate $\bar{r}$ as exogenous variables. To analyze the dynamic system, we have to specify how the net worth ratio $z$ and previous bank lending rate $\bar{r}$ evolve over time. ${ }^{11}$

Let us first derive the dynamic equation of the net worth ratio. Taking the logarithmic derivative of the net worth ratio, we have

$$
\frac{\dot{z}}{z}=\frac{\dot{Z}}{Z}-\frac{I}{K}=\frac{\dot{Z}}{p K} \cdot \frac{p K}{Z}-\frac{I}{K},
$$

\footnotetext{
${ }^{10} \mathrm{We}$ assume that there is a unique steady state.

${ }^{11}$ Although we present a continuous model in this paper, we can also construct a discrete model. Whether the model is continuous or discrete, we can obtain similar results.
} 
where a dot above a variable denotes a time derivative. Since we assume the equity is constant, the evolution of net worth $Z$ is equal to the retained earnings. Taking into account Eq. (4), we have

$$
\dot{Z}=\dot{E}_{s}=F=(1-v)(p Y-\omega N-\bar{r} L) .
$$

Substituting Eq. (44) into Eq. (43), we obtain

$$
\dot{z}=(1-v)\left\{\frac{\tau}{1+\tau} y-\bar{r}(1-z)\right\}-z k(r, z) .
$$

On the other hand, we suppose that the evolution of previous bank lending rate can be expressed as

$$
\dot{\bar{r}}=r-\bar{r} \text {. }
$$

Substituting Eqs. (42a) and (42b) into Eqs. (45) and (46), we obtain a dynamic model which comprises two differential equations,

$$
\begin{aligned}
& \dot{z}=F\left(z, \bar{r} ; i^{a}\right), \\
& \dot{\bar{r}}=R\left(z, \bar{r} ; i^{a}\right) .
\end{aligned}
$$

The steady state of this dynamic model is represented by ${ }^{12}$

$$
\begin{aligned}
& (1-v)\left\{\frac{\tau}{1+\tau} y\left(z^{*}, \bar{r}^{*} ; i^{a}\right)-\bar{r}^{*}\left(1-z^{*}\right)\right\}-z k\left(r\left(z^{*}, \bar{r}^{*}\right), z^{*}\right)=0, \\
& r\left(z^{*}, \bar{r}^{*}\right)=\bar{r}^{*} .
\end{aligned}
$$

At the steady state $\left(z^{*}, \bar{r}^{*}\right)$, evolution of net worth and the capital are the same. The net worth ratio and bank lending rate remain constant.

Making linear approximation of the dynamic model near the steady state to analyze stability, we have a coefficient matrix $A$,

$$
\left(\begin{array}{c}
\dot{z} \\
\dot{\bar{r}}
\end{array}\right)=\left(\begin{array}{ll}
F_{1} & F_{2} \\
R_{1} & R_{2}
\end{array}\right)\left(\begin{array}{l}
z-z^{*} \\
\bar{r}-\bar{r}^{*}
\end{array}\right), \quad A=\left(\begin{array}{ll}
F_{1} & F_{2} \\
R_{1} & R_{2}
\end{array}\right) .
$$

The values of each element are appreciated at the steady state. Taking into account the results of static model, we can express the values as follows: ${ }^{13}$

$$
\begin{aligned}
& F_{1}=(1-z-v)\left(\frac{\tau}{1+\tau}\right) y_{z}+(1-v) \bar{r}-k, \\
& F_{2}=(1-z-v)\left(\frac{\tau}{1+\tau}\right) y_{\bar{r}}-(1-v)(1-z),
\end{aligned}
$$

\footnotetext{
${ }^{12}$ We suppose that the retained earnings $F$, the net worth ratio $z^{*}$, and capital accumulation rate $k^{*}$ are positive at the steady state.

${ }^{13}$ For convenience, we omit the asterisks which express the values of the steady state. Appendix 2 outlines the process to derive Eqs. (50a) and (50b).
} 


$$
\begin{aligned}
& R_{1}=r_{z}, \\
& R_{2}=r_{\bar{r}}-1 .
\end{aligned}
$$

We assume that the following condition is satisfied at the steady state: ${ }^{14}$

$$
1-z-v>0
$$

The system is stable if the following conditions are satisfied:

$$
\begin{array}{r}
F_{1}+R_{2}<0, \\
F_{1} \cdot R_{2}-F_{2} \cdot R_{1}>0 .
\end{array}
$$

But there is no assurance that these conditions are satisfied. The sign of left-hand side of (52b) depends on the value in the following manner:

$$
\begin{aligned}
U= & -(1-v)(1-z)\left(z k_{z}+1+k\right)-(1-z-v)\left\{k_{z} l_{r}^{b}-k_{r}\left(1+l_{z}^{b}\right)\right\} \\
& -(1-v) \bar{r}\left\{l_{r}^{b}-(1-z) k_{r}\right\}+(1-v)(1-z)\left(k_{z}-l_{z}^{b}\right)+k\left(l_{r}^{b}-v k_{r}\right) .
\end{aligned}
$$

When the sign of $U$ is negative, the system is unstable. Taking into account condition (51), it is negative when the absolute value of $l_{z}^{b}$ exceeds the value of $k_{z}$ and $v$ is low. In other words, we can point out financial factors that make an economy unstable as follows:

(1) The bank lending reaction to the net worth ratio exceeds the investment reaction.

(2) Dividend rate is low.

From the static model, we can confirm that these factors make the bank lending rate decrease responding to an increase of the net worth ratio.

On the basis of Minsky's argument, we will investigate the unstable economy. Let us analyze by using a phase diagram. When $r_{z}$ is negative, $R_{1}$ will be also negative. Suppose that $F_{1}>0$, and $R_{2}<0$, the locus of $\dot{z}=0$ is upward sloping and that of $\dot{\bar{r}}=0$ is downward sloping as shown in Fig. 4. The intersection of these loci denoted by $E^{*}$ represents the steady state.

The steady state $E^{*}\left(z^{*}, \bar{r}^{*}\right)$ becomes a saddle point and there is a unique path that converges to it. For example, the economy $A$ can converge to the steady state. But it is unusual for the economy to be on the saddle path. The gaps between the economies on the convergence path and the others will expand cumulatively as time goes by.

Let us consider economy $B$ in Fig. 4 . The net worth ratio tends to increase in the situation of economy $B$. The firm increases investment and bank lending increases. The output of the economy and firm's profit will increase. As demand for funds increase, the bank lending rate rises. This in turn causes investment to decrease. After a while, the firm gets into the red and the net worth ratio will begin to decrease. The bank lending rate will become increasingly higher. The economy continues to decline.

\footnotetext{
${ }^{14}$ From this assumption, $F_{2}$ becomes negative.
} 
Fig. 4 Steady state

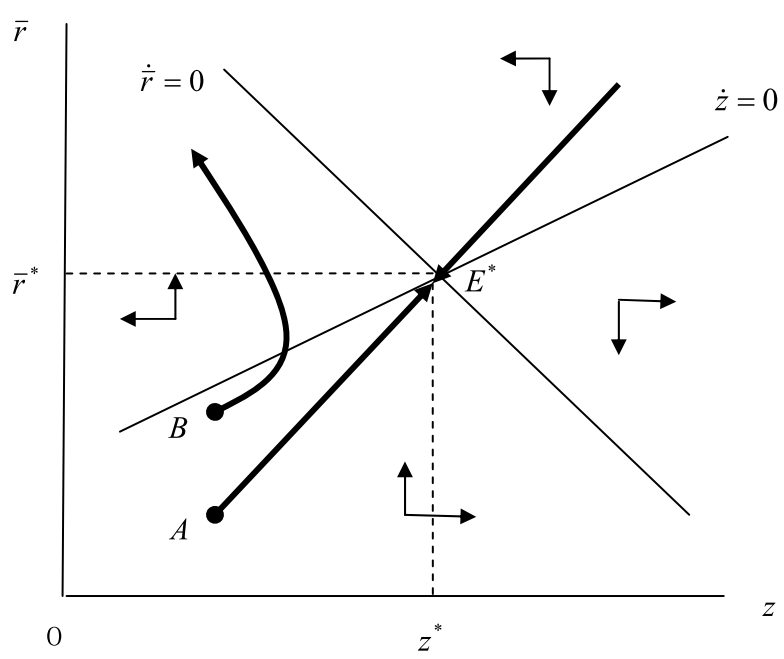

Fig. 5 The effectiveness of monetary policy

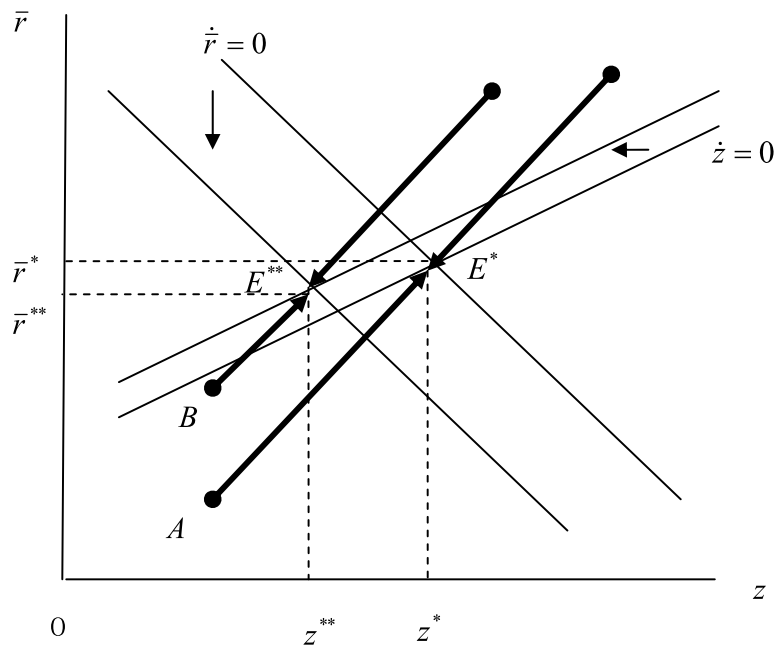

Proposition 2 The dynamic system which consists of the net worth ratio of firm and the bank lending rate may be unstable when the dividend rate is low and the bank lending reaction to the net worth ratio is more elastic than investment reaction.

\subsection{Comparative Analysis of the Steady State}

Finally, let us analyze the effect of monetary policy on the steady state. We will focus on the effect of the decrease of the basic discount rate $i^{a}$.

When the basic discount rate decreases, the $\dot{z}=0$ curve will shift leftward and $\dot{\bar{r}}=0$ curve downward, as shown in Fig. 5 . The net worth ratio at the steady state will decrease. But the bank lending rate will be ambiguous.

$$
\frac{d z^{*}}{d i^{a}}>0, \quad \frac{d r^{*}}{d i^{a}} \lesseqgtr 0 .
$$


The change in the basic discount rate makes the saddle path shift up. Let us show Fig. 5. The economy $B$ was on the divergence path at first as shown in Fig. 4, now is on the convergence path. The reason is that the decrease of the basic discount rate suppresses the excessive increase of bank lending rate. We can see that the monetary policy has a stabilizing effect on the economy.

Proposition 3 When the steady state is a saddle point, the change in the basic discount rate is likely to shift the economy from an unstable path to a convergence path. The monetary policy has a stabilizing effect.

\section{Conclusions}

We constructed a simple macro model on the net worth ratio of the firm. As a result, we have shown that the increase of net worth ratio increases the output-capital ratio in the short-run. Additionally, we pointed out that the excessive reaction of bank lending to the net worth ratio constitutes a serious destabilizing factor for the economy.

We can reconfirm that these results agree well with aspects of Minsky's theory. It is said that we have to have some regulations on bank behavior to stabilize the economy in the long run.

On the other hand, recently, from the view of stock-flow consistent (SFC) approach, it has been pointed out that traditional models such as Taylor and O'Connell often assume oversimplified hypotheses that do not do justice to Minsky's literary analyzes and do not consider the logical implications of these hypotheses. ${ }^{15}$

The SFC models are based on accounting frameworks that consistently integrate financial flows of funds with a full set of balance sheets. They show the logical interrelations between the transactions among the sectors. Passarella [14] analyzed the impact of both capital-asset inflation and consumer credit on the financial soundness of the business sector. We do not take into consideration these elements.

Our model is closer to a traditional model. We must construct a model that is applicable to the analysis of macroeconomic policies.

\section{Competing Interests}

The author declares that he has no competing interests.

Acknowledgements I am very grateful for the comments and suggestions of two referees of this Journal, which led to several improvements in the paper. Of course, all remaining errors are my own.

${ }^{15}$ Some examples of those works are [5, 6] and [14]. 


\section{Appendix 1: The Proof of the Stability of Short-Run Equilibrium}

Making linear approximation of Eqs. (37) and (40) near the short-run equilibrium, we have the following coefficient matrix $T$ :

$$
T=\left(\begin{array}{cc}
-\frac{\tau}{1+\tau} & k_{r} \\
-\frac{(1-v) \tau}{1+\tau} & k_{r}-l_{r}^{b}
\end{array}\right)
$$

The values of each element are appreciated at the short-run equilibrium. The system is stable if Eqs. (38) and (41) are satisfied and the determinant of matrix $T$ is positive. The latter condition is represented by

$$
\operatorname{det}(T)>0
$$

We can confirm that Eq. (A.2) is satisfied.

\section{Appendix 2: The Process to Derive Eqs. (50a) and (50b)}

Making linear approximation of dynamic model near the steady state to analyze stability, we have a coefficient matrix $A$,

$$
\begin{aligned}
\left(\begin{array}{c}
\dot{z} \\
\dot{\bar{r}}
\end{array}\right) & =\left(\begin{array}{ll}
F_{1} & F_{2} \\
R_{1} & R_{2}
\end{array}\right)\left(\begin{array}{l}
z-z^{*} \\
\bar{r}-\bar{r}^{*}
\end{array}\right), \quad A=\left(\begin{array}{ll}
F_{1} & F_{2} \\
R_{1} & R_{2}
\end{array}\right), \\
F_{1} & =(1-v)\left\{\frac{\tau}{1+\tau} y_{z}+\bar{r}\right\}-z\left(k_{r} \cdot r_{z}+k_{z}\right)-k, \\
F_{2} & =(1-v)\left\{\frac{\tau}{1+\tau} y_{\bar{r}}-(1-z)\right\}-z\left(k_{r} \cdot r_{\bar{r}}\right) .
\end{aligned}
$$

The values of each element are appreciated at the steady state. Taking into account the results of static model, we can rewrite Eqs. (B.2) and (B.3) as Eqs. (50a) and (50b) in the main text.

\section{References}

1. Adachi H (1994) Unstable economy and financial factors. In: The theory of macro dynamics. Yuhikaku, Tokyo, pp 293-324 (Japanese edn)

2. Asada T (1987) Government finance and wealth effect in a Kaldorian cycle model. J Econ 47:143166

3. Bernanke BS, Gertler M (1989) Agency cost, net worth, and business fluctuations. Am Econ Rev 82:901-921

4. Delli Gatti D, Gallegati M (1990) Financial instability, income distribution and the stock market. J Post Keynes Econ 12:356-374

5. Dos Satos C (2005) A stock-flow consistent general framework for formal Minskian analyses of closed economies. J Post Keynes Econ 27:711-735

6. Dos Satos C (2006) Keynesian theorising during hard times: stock-flow consistent models as an unexplored 'frontier' of Keynesian macroeconomics. Camb J Econ 30:541-565

7. Fisher I (1933) The debt-deflation theory of Great Depression. Econometrica 1:337-357 
8. Greenwald B, Stiglitz JE (1993) Financial market imperfection and business cycles. Q J Econ 108:77114

9. Kaldor N (1940) A model of the trade cycles. Econ J 50:78-92

10. Keynes JM (1936) The general theory of employment, interest, and money. Macmillan \& Co, London

11. Lavoie M (1995) Interest rate in post-Keynesian models of growth and distribution. Metroeconomica 46:146-177

12. Minsky HP (1975) John Maynard Keynes. Columbia University Press, New York

13. Modigliani F, Miller M (1958) The cost of capital, corporation finance and the theory of investment. Am Econ Rev 48:261-297

14. Passarella M (2012) A simplified stock-flow consistent dynamic model of the systemic financial fragility in the 'New Capitalism'. J Econ Behav Organ 83(3):570-582

15. Taylor L, O’Connell SA (1985) A Minsky crisis. Q J Econ 100:871-885

16. Tobin J (1969) A general equilibrium approach to monetary theory. J Money Credit Bank 1:15-29 